CORPUS $\begin{aligned} & \text { Corpus } \\ & \text { Archivos virtuales de la alteridad americana }\end{aligned}$

Vol. 10, No. 1 | 2020

Enero / Junio 2020

\title{
Museos del honor
}

\section{Carlos Masotta}

\section{(2) OpenEdition}

\section{Journals}

Electronic version

URL: http://journals.openedition.org/corpusarchivos/3428

DOI: $10.4000 /$ corpusarchivos. 3428

ISSN: 1853-8037

\section{Publisher}

Diego Escolar

\section{Electronic reference}

Carlos Masotta, « Museos del honor», Corpus [En línea], Vol. 10, №. 1 | 2020, Publicado el 28 junio 2020, consultado el 02 julio 2020. URL : http://journals.openedition.org/corpusarchivos/3428 ; DOI : https://doi.org/10.4000/corpusarchivos.3428

This text was automatically generated on 2 July 2020.

Licencia Creative Commons: Atribución-NoComercial 2.5 Argentina (CC BY-NC 2.5 AR) 


\title{
Museos del honor
}

\author{
Carlos Masotta
}

1 Cuando Mariana Sirimarco me invitó a colaborar en este Debate, me sugirió que visitara el Museo de Gendarmería Nacional. Los numerosos uniformes expuestos en sus diferentes salas me recordaron algunos testimonios de indígenas que había relevado años atrás en la Patagonia.

2 En un pequeño pueblo de la cordillera chubutense, entrevisté en 2000 a quien me habían referenciado como protagonista de un encuentro con un monstruo en uno de los lagos de la zona. Efectivamente, mi entrevistado describió con detalles el episodio, a la vez que comentó la existencia de una tradición mapuche sobre esas apariciones. Tanto su padre como su abuelo sabían sobre el tema. Recuerdo la gravedad con que relató aquel episodio: “...y lo vimos al lado de nuestra balsa; ¡doce metros le calculé al animal!". En un tono muy similar (una mezcla de certeza y asombro) describió otro momento de su vida, cuando por primera vez vistió el uniforme al ingresar al servicio militar. Concluyó la descripción erguido, afirmando: “j...y qué orgullo!”.

3 Años después, en un paraje cercano al anterior pero en la provincia de Río Negro, un miembro de una comunidad mapuche que se encontraba en conflicto por la propiedad de sus tierras me narró sus encuentros personales con lo que solemos llamar "fuerzas sobrenaturales". Me contó que, siendo niño, una parálisis en sus piernas le impedía caminar y, para remediarlo, su padres recurrieron a una mujer shamán mapuche quien mandó sacrificar una vaca, abrir su vientre y depositarlo allí durante un momento. Luego del rito comenzó a dar sus primeros pasos. Igual que el caso anterior, el servicio militar ocupó un lugar en la narración. Evocó su uniforme, pero fue un poco más allá y concluyó arremangándose la camisa para mostrarme un tatuaje en uno de sus brazos. Me explicó que por "buena conducta" sus superiores lo habían marcado allí con el escudo de la Fuerza Aérea. «Este es mi diploma», dijo. 


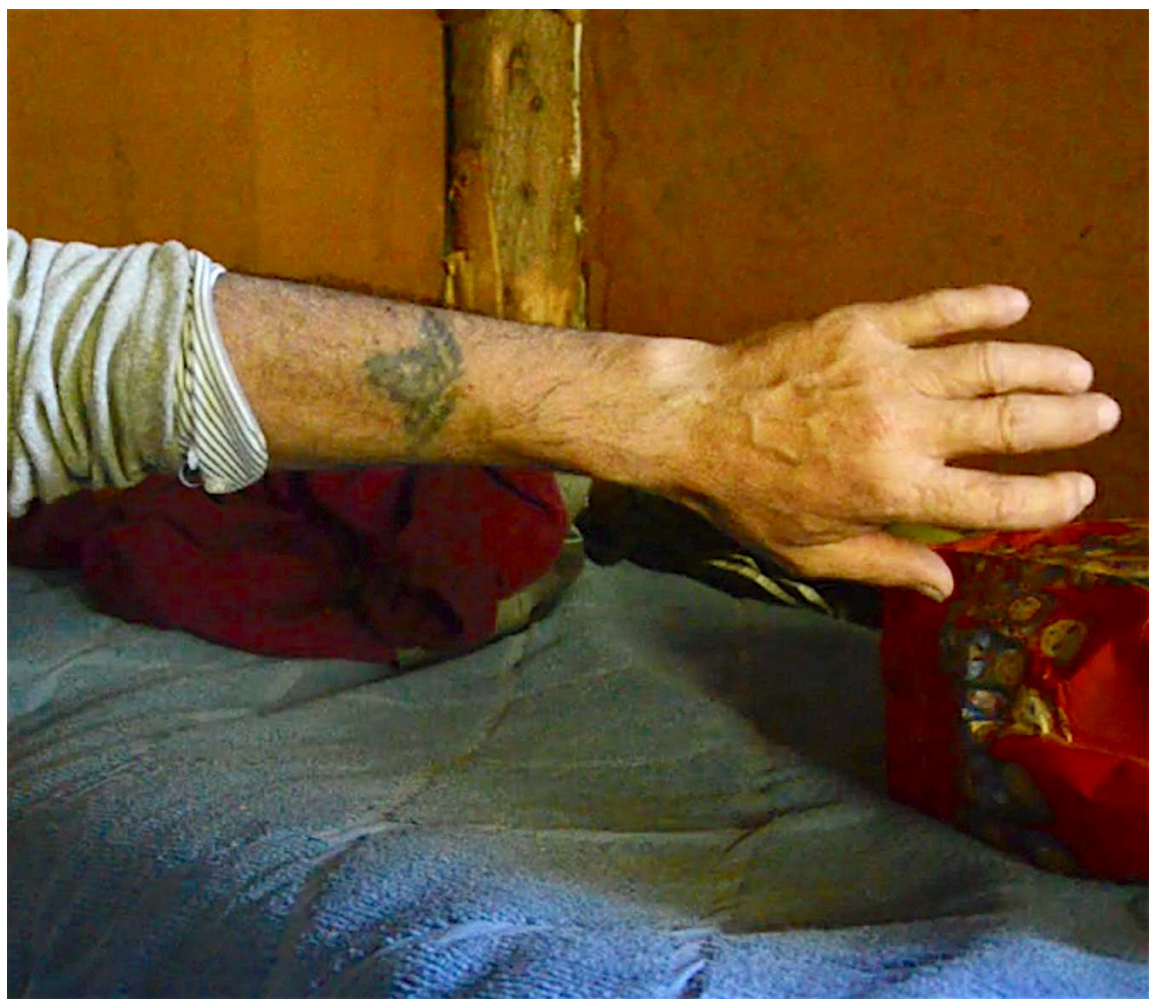

Imagen No 1. Tatuaje con figura del escudo de la Fuerza Aérea.

(Fuente: Carlos Masotta)

4 Los dos entrevistados eran hombres mayores y con profundos conocimientos sobre el territorio que habitaban. Lo que me llamó la atención de sus relatos fue la articulación del poder territorial con el sentimiento de orgullo relacionado con su contacto con las FF.AA. y que, en ambos, el cuerpo apareciera como un lugar especial de inscripción. Como si el cuerpo hubiera registrado por igual esas dos potencias: las que el conocimiento mapuche adjudica al territorio y las honoríficas dispuestas por las FF.AA.

En el Museo de Gendarmería las citas a los pueblos originarios son escasas, pero mi primera impresión fue que algo de aquel diálogo entre potencias territoriales $\mathrm{y}$ corporales se daba entre sus vitrinas. En sus cinco salas, el museo expone objetos históricos (armas, documentos, fotografías, equipos de campaña, de telecomunicaciones, medios de movilidad y hasta un helicóptero, entre otros), pero el objeto que más se repite es el uniforme. "La Fuerza" (tal la autodenominación) se creó en 1938 en especial vínculo con el control de los Territorios Nacionales que, por entonces, representaban la mitad aproximada de la superficie del mapa nacional. Gendarmería nace en el período de auge del conservadurismo como un brazo especial o apéndice del Ejército, contemporáneo a la constitución de este último en sujeto político, tras el golpe de Estado que encabezó el general del Ejército José Félix Uriburu en 1930.

La institución cuenta hoy más de 80 años, pero su museo fue inaugurado recien en 1985. Esto no parece un dato menor si se considera que, fundada al calor del militarismo, su museo se inicia en el momento de la llamada "apertura democrática" posterior a la última dicadura militar y, especialmente, en el mismo año del Juicio a las Juntas Militares responsables del accionar del terrorismo de Estado y de crímenes de lesa humanidad, donde Gendarmería operó como una de las fuerzas participantes. En este 
sentido, el Museo es un efecto de la particular aporía de darse una historia en el preciso momento en que el pasado reciente de la institución ha sido impugnado por su responsabilidad y participación en los peores crímenes.

7 Antes de conocer el Museo, imaginé que en él encontraría mucha cartografía y una importante recurrencia al discurso territorial. No fue así. Esto último está presente, pero lo que redunda diseminándose por todo el espacio, como ya dijimos, es el objeto uniforme. Montados en maniquíes, pertenecientes a diferentes épocas y grados, se corporizan con solemnidad (muchos en vitrinas). Son vestimentas de trabajo pero, fundamenalmente, respaldan la investidura simbólica del cuerpo colectivo militarizado.

El tono general del guión museográfico parece estar dado por una formación especial de esculturas, uniformes y objetos, organizada en la primera sala. Cuando el visitante ingresa se enfrenta a los bustos del general Manuel Calderón (fundador de Gendarmería) y del general Martín Güemes (prócer referente de la institución). Los bustos se encuentran secundados por cuatro maniquíes uniformados, dispuestos a su vez como custodios de una extensa sucesión de banderas argentinas en sus mástiles ceremoniales manuales. En el centro exacto de las banderas fue colocado un antiguo hito limítrofe (estructura piramidal de hierro utilizada para la marcación de las fronteras internacionales). Uniformes corporizados, banderas, hito. Los sentidos dispares de estos elementos son asociados metonímicamente (todos de pie y de una contextura similar). No es simplemente la exposición de objetos antiguos en función de una narración histórica, sino una escenificación organizada en términos simbólicos: casi como el diorama de un rito patriótico. Delante de esta línea, entre los bustos mencionados, una vitrina expone un suntuoso sable dorado. La centralidad del objeto en tal marco (bustos, banderas, uniformes) parece resguardar una pieza especial. Pero allí no se muestra un objeto original a secas sino la réplica del sable que perteneciera al general Güemes y que es considerado el símbolo mayor de la institución (parte, a su vez, del uniforme en los contextos ceremoniales de mayor solemnidad). ${ }^{1}$

En resumen, es un carácter honorífico antes que histórico el que organiza la exposición. En toda las salas, a los objetos utilitarios y a los documentos se suman medallas, banderines, escudos, fotos de desfiles o actos públicos que suman al relato histórico este otro que, permenentemente, lo sostiene en la moralidad de lo actuado. Se mencionan acontecimientos (la captura de bandoleros, el enfrentamiento con la primera guerrilla en Salta en 1964, los gendarmes muertos en la guerra de las Malvinas, las misiones internacionales en los años recientes, entre otros) pero es la repetición de piezas honoríficas, la que explícitamente los caracteriza. En contigüidad con el capítulo más dramático del recorrido ("La Gesta de Malvinas"), un enorme recuadro reproduce el "Decálogo del Gendarme" (de 1944 y actualizado en 2010). En su punto primero declara: "Tengo el honor de ser gendarme".

Este guión paralelo, este museo del honor, juega la carta del monumento, de la que la museografía en general dispone. El juego al monumento es propio del museo del honor. Exalta y afirma, al igual que el discurso del acto patriótico, a la vez que produce un profundo silencio sobre sí, pues ocluye cualquier revisión o autocrítica sobre lo actuado. Como comentara Julian Pitt-Rivers, "(el honor) ...como la magia, se valida a sí mismo recurriendo a los hechos -a los que impone sus propias interpretaciones..." (1979, p. 17). Casos como la participación de la institución en la masacre de Rincón Bomba (1947) o en la represión ilegal de la última dictadura son omitidos. Pero dada la magnitud de tales hechos, el silencio del Museo alrededor de ellos no puede ser más 
ruidoso. En 2010, quien era el director desde su inauguración fue condenado por aplicación de torturas a prisioneros en un campo de concentración en Córdoba durante la última dictadura (Escolar, 2017).

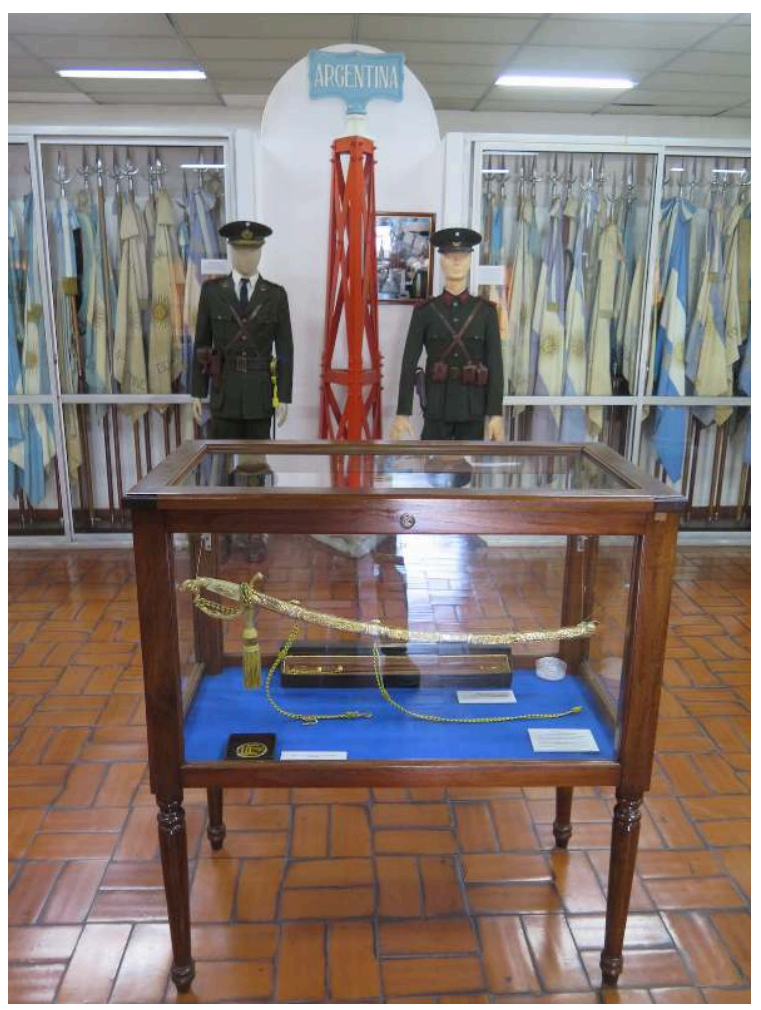

Imagen No 3. Sala de ingreso al Museo de Gendarmería Nacional.

(Fuente: Carlos Masotta)

\section{Museo/monumento}

11 En la década de 1990, Andreas Huyssen (2002) señalaba la fluidez, que aparecía como una novedosa característica del fin de siglo posmoderno, entre el museo, el memorial y el monumento. Con todo, los museos gestionan desde siempre un espíritu monumental que se encuentra en sus bases: el gusto por el neoclásico en sus edificios del siglo XIX o por las vanguardias en los del XX. Desde el iluminismo se presentaron como el principal escenario de la ciencia y el arte definidos en clave universal. Sus piezas pueden ser únicas y sus colecciones incompletas, pero es la misma idea de colección la que produce el efecto de totalidad que arrastra todo universalismo. El museo expone y se expone en esta misma función. Es un operador de memoria colectiva porque antes lo es del tiempo. La colección es a la vez destructora y constructora de contextos (Stewart, 2013). La colección museográfica desplaza al objeto de su contexto cultural de uso $\mathrm{y}$, en función de la exhibición y la guarda, recrea uno temporalmente complejo en su devenir contemporáneo como reliquia. El museo es como el enorme relicario de un tiempo universal al que silenciosamente se rinde culto.

Para la Argentina, esto queda bien sintetizado por la escultura del frontis del Museo de Ciencias Naturales de La Plata: un ángel (la ciencia) vuela con una palma de la victoria en alto, mientras con la otra mano levanta el paño que cubre la esfera del mundo. Pero pronto (o al mismo tiempo) el universalismo del museo fue traicionado por el 
nacionalismo. El edificio fue adornado en su contorno exterior por 20 bustos de "hombres de ciencia" universal (Lamark, Darwin, D’Orbigny...), mientras que la rotonda de ingreso se decoró con pinturas murales de paisajes e indígenas argentinos. Finalmente, en 1923 en el centro de ese círculo, se colocó un busto mayor, el de su fundador, el argentino Francisco P. Moreno. Es decir, un templo de la ciencia universal que, sin embargo, en su interior aloja a la acción de la ciencia nacional sobre su territorio y población nativa. El universalismo es instrumental del particularismo; el Estado-nación como agente civilizador es una de sus perdurables encarnaciones.

Es conocida la historia de los indígenas capturados por el Ejército que fueron recluidos en el Museo de la Plata al final de la llamada "Conquista del Desierto". ${ }^{2}$ Los indígenas cautivos no solo fueron objeto de estudio singular del gabinete de antropología, también pintores y escultores contratados por la misma institución los tomaron como modelos de sus obras. Fueron retratados en escenas prehistóricas como anónimos indígenas en los óleos murales dispuestos en el ingreso al museo (por ejemplo, en "Descuartizando un gliptodonte" o "Cacería prehistórica", de Luiggi De Servi). El escultor Víctor de Pol (el mismo que creó el ángel de la ciencia del frontis) realizó la escultura de un indígena desnudo tomando como modelo al cacique Foyel. La escultura realizada por de Pol lleva el rostro del jefe indígena pero sin identificarlo. La obra fue diseñada para el conjunto alegórico que adorna el pedestal de la estatua Fray Trejo y Sanabria, el fundador de la Universidad Nacional de Córdoba. La escultura muestra al indígena desnudo y sentado junto a niños tambien indígenas y desnudos ante una enorme cruz que se eleva sobre ellos. A un lado y a su espalda, una mujer levanta un manto repitiendo la misma retórica del "descubrimiento" a la vez científico y civilizador que usara el escultor en el frontis del Museo de La Plata.

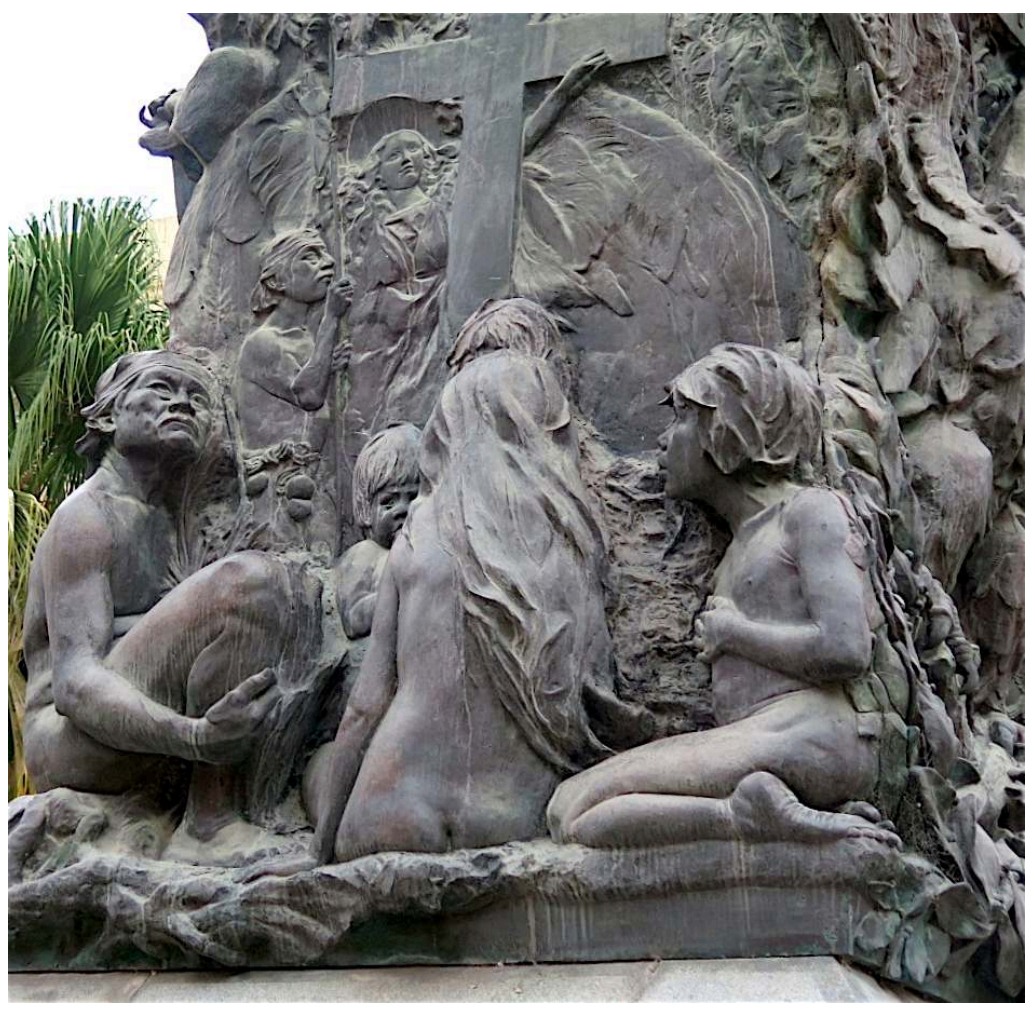

Imagen $N^{0}$ 2. Figura del cacique Foyel y jóvenes indígenas en el pedestal del monumento a Fray Trejo y Sanabria, realizado por Víctor de Pol en 1903, Universidad Nacional de Córdoba. (Fuente: Carlos Masotta) 
En el mismo año, 1889, se concluyó ese museo y se inauguró en la ciudad de Buenos Aires el Museo Histórico Nacional. Se solicitó a Manuel Blanes ilustrar una de sus paredes con el que sería el cuadro más grande de la pintura de tema histórico de Argentina: "La revista del Río Negro" también conocida como "La conquista del desierto". El flamante Museo lo presentaría como la escena culminante de la saga nacional. En relación con lo comentado más arriba, nótese que en tal escena la "conquista" se representa mediante una extensa sucesión de figuras ecuestres uniformadas en pose solemne y portando sables. Solo el general Roca, que encabeza al grupo, se muestra en una pose relajada llevando un par de prismáticos en actitud reflexiva (el jefe que falta al protocolo refuerza su poder). Cuatro décadas después, una exacta copia de esta figura de Roca será volcada en un molde de bronce para la inauguración del monumento al militar que se encuentra en la plaza de esa mole monumental conocida como Centro Cívico de la ciudad de Bariloche. Podríamos continuar con otros casos de deriva entre museos y monumentos, pero lo que me interesa señalar aquí es que, en Argentina, ambos compartieron sus potencias alegorizantes frecuentemente utilizadas para eufemizar el ejercicio de la violencia sobre la población indígena. Y que esta última opera no solo marcando a una minoría subalternizada sino, asimismo, inscribiéndose una y otra vez como prototipo honorífico de dominación.

Así, las FF.AA. pueden producir museo pues son vicarias de tal prototipo. El Estado conserva en ellos además de objetos, fundamentalmente, la sacralidad de su violencia.

\section{Uniforme y alteridad}

La sala del Museo de Gendarmería que reúne mayor documentación histórica es la más pequeña y, de alguna forma, también la más curiosa. Parece dedicada a la intervención de la institución en la ruralidad alrededor de la década de 1940. Dos hileras de vitrinas y objetos forman un angosto pasillo donde se exponen expedientes y prontuarios originales de las capturas de los famosos bandoleros Bailoreto y "Mate Cosido". En esa línea también se exponen antiguos garrotes y armas de policía, esposas, otros elementos utilizados en la captura de reos y aparatos de medición antropométrica. En consonancia con esas tecnologías, la sala concluye con la distibución de elementos de una antigua unidad de sanidad coronados por una vitrina central que expone un maniquí cubierto por una manta tejida a telar indígena. A un costado de la prenda, sobre un atril, el libro "El complejo tehuelche" publicado en 1949 y escrito por el médico de Gendarmería Federico Escalada. La sala se organiza con una secuencia disciplinaria (control policial y sanitario), pero la vitrina dedicada a Escalada produce un desvío. El maniquí ya no porta un uniforme sino un rústico tejido de telar aborigen. A un costado, una foto muestra al propio Escalada uniformado, posando junto a Agustina Quinchamal ("tehuelche meriadional pura"), su principal consultante, que lleva sobre sus hombros la prenda expuesta. ¿Fue un obsequio de la indígena al médico gendarme? ¿Se trata de una pieza de colección etnográfica? Tal vez. Escalada participó de las primeras campañas arqueológicas y antropológicas a la Patagonia y la colección entraba dentro de sus actividades de campo. En el otro extremo de la foto hay un hombre de perfil con una campera de cuero y un gorro de lana, que si bien no constituyen un uniforme, se identifican como una vestimenta especial de expedicionario. Se trata del antropólogo José Imbelloni, por entonces director del Instituto de Antropología de la Univerdidad de 
Buenos Aires. La imagen recrea una alteridad militar-indígena-antropólogo marcada especialmente por la disposición de los cuerpos y por las vestimentas uniforme/manta tejida. En el contexto del Museo, la vitrina repite esta relación de alteridad. Con todo su desvío, es singular porque se desplaza por un momento del eje honorífico hacia otro etnográfico. Pero su ubicación en el interior de esa sala y entre instalaciones de medicina colocan tal relato en un marco de excepcionalidad. Cuando realicé la visita, otra foto mostraba a Agustina Quinchamal casi de espaldas, con el objeto de documentar el tocado tradicional de sus largas trenzas. La intención de la imagen era evidentemente etnográfica, aunque se exponía apoyada sobre un viejo nebulizador. Si bien la vitrina de Escalada-Quinchamal era el único capítulo dedicado a una relación duradera de Gendarmería con personas que no pertenecieran a la institución, por defecto, la excentricidad del caso parecía confirmar que el Museo operaba de puertas para adentro. En el plano de la ciudad de Buenos Aires, su ubicación muy periferica indicaría lo mismo. En contraste con la repetición de los impecables uniformes, el raído tejido indígena expuesto parecía marcar más aún una distancia infranqueable.

En los últimos años, la antropología argentina ha observado a las FF.AA. y de seguridad en tanto elite moral vinculada a prácticas, símbolos y sentimientos honoríficos (Badaró, 2006, 2009, 2018; Frederic, 2010, 2012; Guber, 2013); el caso de Gendarmería y de su museo fue desarrollado pormenorizadamente por Diego Escolar (2017). En esta perspectiva, el uniforme ha sido señalado recurrentemente como un objeto particularmente activo y en contraste explícita o implícitamente con la vestimenta civil (Frederic, 2013; Sirimarco, 2009, 2013, 2014).

Típico aglutinante de las formaciones estamentarias según la conocida caracterización de Max Weber, el honor hace del pasado una suceción de acciones heroicas que confirman la existencia de una comunidad moral. El uniforme es su inscripción corporal pero también es objeto de identificación. Una pieza clave del lenguaje de mando y dominio estatal sobre la población civil. Se trata de una singular pieza del exhibicionismo en la gestión de la violencia estatal y, en este sentido, su valor de exposición es tanto interno como externo al museo. Mientras ese espacio interior conserva el prestigio del uniforme, en el exterior los movimientos sociales y la cultura popular lo exponen a permanentes actualizaciones. El primer logo de la asociación Madres de Plaza de Mayo mostraba una gorra militar sobre un banco rodeada de pañuelos que la interpelaban. En la Argentina, el uniforme militar es tecnología gubernamental impugnada y a la vez reproducida por su temporalidad de honor y silencio.

\section{BIBLIOGRAPHY}

Badaró M. (2006). La construcción simbólica de la identidad del Ejército Argentino. Entrepasados. Revista de Historia, XV(30), 7-28.

Badaró, M. (2009). Militares o ciudadanos. La formación de los oficiales del Ejército Argentino. Buenos Aires: Prometeo. 
Badaró, M. (2018). El Ejército Argentino actual: una elite sin poder. Voces en el Fénix, 73, 62-67.

Escolar, D. (2017). Gendarmería. Los límites de la obediencia. Buenos Aires: SB.

Frederic, S. (2012). Fotografías de la Configuración Profesional de los Militares en el Contexto de su Declinación como Elite Estatal. En: M. Plotkin y E. Zimmerman (Eds.), Las prácticas del Estado, (pp. 210-234). Buenos Aires: Edhasa.

Frederic, S. et al. (2010). La formación militar como formación moral: transmisión adquisición de saberes teóricos prácticos en las Fuerzas Armadas. En S. Frederic et al. (Comp.), El Estado argentino y las profesiones liberales, económicas y Armadas, (pp. 387-420). Buenos Aires: Prehistoria ediciones.

Guber, R. (2013), Como un cierre. Igualdad, honor y amistad entre contendientes directos, después de Malvinas. Tabula Rasa, 19, 11-27.

Huyssen, A. (2002) En busca del futuro perdido. Cultura y memoria en tiempos de globalización. Mexico: FCE.

Sirimarco, M. (2009). De civil a policía. Una etnografía del proceso de incorporación a la institución policial. Buenos Aires: Editorial Teseo.

Sirimarco, M. (2013). A vida com farda. A vestimenta policial como relato institucional em disputa. Revista Brasileira de Ciências Sociais, 28(82), 31-44.

Sirimarco, M. (2014). La cosa y la palabra. Relato y emocionalidad en un museo policial. Revista del Museo de Antropología, 7(1): 177-188.

Pitt-Rivers, J. (1979). Antropología del honor o política de los sexos. Barcelona: Crítica.

Stewart, S. (2013). El Ansia. Narrativas de la miniatura, lo gigantesco, el souvenir y la colección. Rosario: Beatriz Viterbo.

\section{NOTES}

1. El uniforme de Gendarmería fue regulado por un decreto de 1957 donde se establece que a los cadetes se les hará entrega de una réplica reducida de dicho sable y a los altos cargos una de temaño original. El escudo institucional representa dos sables cruzados unidos por una cinta con los colores de la bandera nacional con unas hojas de roble debajo. La bandera de la institución repite la figura del escudo sobre color verde. Una muestra de la vigencia del uso político de tal símbolo se expuso publicamente en diciembre de 2019 cuando la ministra de Seguridad del gobierno saliente, Patricia Bulrich, fue obsequiada por la misma Gendarmería con un sable. En la lujosa caja-vitrina que lo guardaba habian sumado un cartel con la insólita leyenda: "No voy a hacer la injusticia de querer tirar a un gendarme por la ventana". La frase era una cita de lo expresado por la Ministra luego de producirse masivos reclamos por la desaparición de Santiago Maldonado en 2017, después de que un grupo de Gendarmería reprimiera el reclamo teritorial de una comunidad mapuche en la provincia de Chubut.

2. Ver el Debate sobre Restituciones en CORPUS, vol.1 (1), 2011. 


\section{AUTHOR}

\section{CARLOS MASOTTA}

Universidad de Buenos Aires- Instituto Nacional de Antropología y Pensamiento Latinoamericano y Consejo Nacional de Investigaciones Científicas y Técnicas, Argentina.

Correo electrónico: cmasott@hotmail.com 